\title{
Терагерцевый ближнепольный отклик в лентах графена
}

\author{
(ㄷ П.А. Алексеев ${ }^{1}$, Б.Р. Бородин ${ }^{1}$, И.А. Мустафинн ${ }^{1}$, А.В. Зубов ${ }^{2}$, С.П. Лебедев ${ }^{1}$, А.А. Лебедев ${ }^{1}$, \\ B.H. Трухин ${ }^{1,2}$ \\ ${ }^{1}$ Физико-технический институт им. А.Ф. Иофффе РАН, Санкт-Петербург, Россия \\ ${ }^{2}$ Университет ИТМО, Санкт-Петербург, Россия \\ E-mail: npoxep@gmail.com
}

Поступило в Редакцию 21 февраля 2020 г.

В окончательной редакции 9 апреля 2020г.

Принято к публикации 29 апреля 2020г.

\begin{abstract}
Сообщается о результатах экспериментального исследования рассеяния и ближнепольного взаимодействия терагерцевого электромагнитного поля с лентами графена вблизи металлического зонда атомно-силового микроскопа. Показано усиление ближнепольного терагерцевого рассеяния в лентах по сравнению с имеющим место в случае неструктурированного графена. Обнаружено возникновение резонансных пиков в области $0.2-1.6 \mathrm{THz}$ в спектрах рассеяния терагерцевого излучения на лентах графена в присутствии зонда, что, возможно, обусловлено взаимодействием излучения с плазмонами в лентах.
\end{abstract}

Ключевые слова: графен, плазмон, терагерцевое излучение, ближнее поле.

DOI: 10.21883/PJTF.2020.15.49745.18256

На протяжении последних лет пристальное внимание уделяется исследованию взаимодействия терагерцевого (THz) излучения со структурами на основе графена $[1,2]$. В первую очередь это связано с активным поиском новых материалов для создания дешевых, быстрых и высокочувствительных детекторов THz-излучения, функционирующих при комнатной температуре. Недавние исследования графена продемонстрировали перспективность этого материала в качестве основы для создания элемента оптоэлектронных устройств THz-диапазона [3-5]. Это связано с большой подвижностью носителей заряда в графене, обусловленной фундаментальными физическими законами и симметрией его кристаллической решетки. Графен отличается в этом отношении от „классических“ полупроводниковых материалов ввиду наличия у носителей заряда так называемого псевдоспина. Эта величина, с одной стороны, должна сохраняться, а с другой - меняет знак при отражении носителя заряда назад. Таким образом, процессы рассеяния электронов оказываются подавленными, благодаря чему у графена аномально высокая длина свободного пробега носителей. Кроме того, исследование взаимодействия THz-излучения с электронными подсистемами низкоразмерных систем может существенно развить наше представление о зонной структуре квазиодномерных проводников. Дело в том, что ширина запрещенной зоны графеновых нанолент шириной до $100 \mathrm{~nm}$ составляет единицы $\mathrm{meV}$, что соответствует кванту излучения THz-диапазона. В силу одномерности рассматриваемых объектов их отклик на излучение должен носить резонансный характер [6]. Другим важным вопросом, на который еще предстоит получить ответ, является роль коллективных возбуждений электронной подсистемы при взаимодействии углеродных наноструктур с THz-излучением [7]. Как известно, графен обладает сильным плазмонным откликом на
THz-частотах, что обусловлено как высокой плотностью, так и малой коллективной эффективной массой свободных носителей заряда [8]. Поэтому весьма актуальным является исследование взаимодействия электромагнитного излучения в терагерцевом спектральном диапазоне с зондом сканирующего зондового микроскопа (С3М) вблизи графеновой ленты. Цель настоящей работы состоит в исследовании терагерцевого ближнепольного отклика от лент однослойного графена.

Для получения пленок монослойного графена использовался метод термического разложения поверхности $\mathrm{SiC}$ [9]. В качестве подложки использовались высокоомные пластины $6 H-\mathrm{SiC}$ с ориентацией $(0001) \pm 0.25^{\circ}$ (Si-грань). Границы монослойных графеновых лент были сформированы методом локального анодного окисления (ЛАО). Метод ЛАО является методом безмасочной зондовой литографии и позволяет создавать изолирующие области оксида графена с разрешением $\sim 10 \mathrm{~nm}$ [10]. Для протекания процесса окисления необходимо присутствие поверхностной пленки воды (влажность > 50\%), a также приложение постоянного электрического напряжения между зондом атомно-силового микроскопа и поверхностью графена. Образующийся в результате электрохимической реакции кислород окисляет графен только в области водного мениска между зондом и поверхностью, что и обеспечивает высокое пространственное разрешение. Области оксида графена были сформированы при относительной влажности 60\%, напряжении на зонде $-20 \mathrm{~V}$ и скорости сканирования $1 \mu \mathrm{m} / \mathrm{s}$ с использованием C3M NtegraAura (NT-MDT). На рис. 1 показано распределение поверхностного потенциала, полученное методом Кельвин-зонд микроскопии участка поверхности графена, на котором проводилось окисление. Светлые горизонтальные полосы (с более высоким значением поверхностного потенциала) шири- 


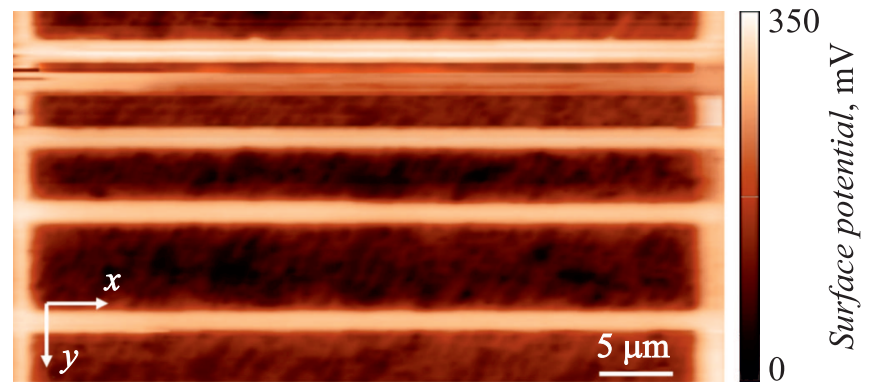

Рис. 1. Распределение поверхностного потенциала участка поверхности графена, на котором сформированы области оксида графена (светлые полосы).

ной $\sim 1 \mu \mathrm{m}$ являются областями с оксидом графена. Ранее было показано, что поверхностный потенциал полностью окисленного графена на поверхности $6 H-\mathrm{SiC}$ выше потенциала неокисленного графена [10]. Ширина графеновых лент составляла $0.5,2.5,3.6$ и $6 \mu \mathrm{m}$.

Терагерцевый безапертурный ближнепольный микроскоп, используемый в настоящей работе, представляет собой когерентный THz-спектрометр с временны́м разрешением с интегрированным в него атомно-силовым микроскопом на базе C3M NanoEducator. Детальное изложение особенностей работы установки и принципиальная схема представлены в $[11,12]$. В терагерцевом когерентном спектрометре после расщепления исходного оптического луча на два световых импульса пучок накачки проходит оптическую линию задержки и попадает на THz-эмиттер, вызывая генерацию THz-излучения с частотой импульсов $\sim 50 \mathrm{kHz}$. THz-излучение с помощью пары параболических зеркал собиралось и фокусировалось на острие зонда. Зонд представляет собой вольфрамовую проволоку длиной $\sim 6 \mathrm{~mm}$, заостренную путем электрохимического травления, оканчивающуюся конусом длиной 150-1000 $\mu \mathrm{m}$, с радиусом закругления вписанной в конец зонда сферы $\sim 100-300 \mathrm{~nm}$ и углом при его вершине $\sim 20^{\circ}$. Рассеянное и отраженное THz-излучение собиралось и направлялось на электрооптический детектор. Регистрация THz-излучения осуществлялась в геометрии зеркального отражения вперед при угле падения $\sim 70^{\circ}$. При этом в детектор попадало как зеркально отраженное от поверхности образца излучение, так и излучение, рассеянное от системы зонд-объект. Для непосредственного выделения терагерцевого дифференциального сигнала, обусловленного компонентами ближнего поля, взаимодействующими с нанообъектом, применялась техника двойного синхронного детектирования. При этом последовательно выделялись как основной THz-сигнал на частоте модуляции THz-излучения ( $\sim 50 \mathrm{kHz})$, падающего на систему зонд-объект, так и сигнал на частоте вертикальных колебаний зонда $(\sim 10 \mathrm{kHz})$. При изменении величины задержки между зондирующим импульсом и импульсом накачки проводилась запись волновой формы основного
THz-сигнала и сигнала на частоте колебаний зонда. Спектральное разрешение составляло $0.05 \mathrm{THz}$.

Для обнаружения участка поверхности с графеновыми лентами на обратной стороне подложки были сделаны метки, обнаруживаемые в оптическом микроскопе. Таким образом, точность начального позиционирования зонда относительно центра области с графеновыми лентами составила $\sim 5 \mu \mathrm{m}$. Следует отметить, что, к сожалению, С3М NanoEducator не обладает возможностью измерения распределения поверхностного потенциала для более точного позиционирования зонда относительно краев лент. Дальнейшее перемещение зонда производилось с помощью пьезосканера с точностью $1 \mathrm{~nm}$.

Для подтверждения того, что регистрируемое рассеянное THz-излучение обусловлено взаимодействием ближнепольной компоненты THz-поля, генерируемой зондом, с образцом, были исследованы кривые подвода (зависимость амплитуды колебаний зонда и величины терагерцевого дифференциального сигнала от расстояния между зондом и исследуемым объектом). Расстояние, на котором происходил рост дифференциального сигнала, составляло менее $100 \mathrm{~nm}$. Это примерно соответствует величине радиуса закругления зонда.

В ходе экспериментов были получены волновые формы THz-импульса (временна́я зависимость дифференциального сигнала, пропорционального величине терагерцевого ближнего поля возле зонда), образованные в результате взаимодействия ближнепольной $\mathrm{THz}-к о м-$ поненты с различными образцами: пленка $\mathrm{Au}$, монослой графена и ленты на основе монослоя графена. На рис. 2, a приведены спектральные распределения рассеянного THz-излучения (ближнепольный отклик, полученный в режиме поддержания постоянной амплитуды колебаний зонда), зарегистрированного для пленки золота, слоя неструктурированного графена, и спектральное распределение исходного THz-излучения, падающего на зонд. Спектры были получены с помощью преобразования Фурье волновых форм с одинаковым временны́ интервалом. Поскольку эксперименты проводились в воздушной среде, содержащей молекулы воды, в полученных спектрах THz-излучения присутствуют пики поглощения на парах воды. В исходном спектре THz-излучения отмечены линии поглощения $B, C$ и $D$, которые соответствуют линиям поглощения молекул воды в области $0.75,1.17$ и $1.67 \mathrm{THz}$ [13]. В спектре, обусловленном ближнепольным взаимодействием с графеном, присутствуют эти же линии поглощения молекул воды, а также линии поглощения, которые практически отсутствуют в полученном спектре возбуждающего излучения: линии $A$ и $E$. Отметим, что линии $B$ и $C$ проявляются сильнее в спектре ближнепольного сигнала. Данный эффект свидетельствует об усилении погло-

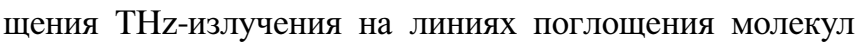
$\mathrm{H}_{2} \mathrm{O}$, когда происходит взаимодействие ближнепольной компоненты THz-поля со слоем графена. Подобное явление отмечалось в работе [14], в которой исследовалось 

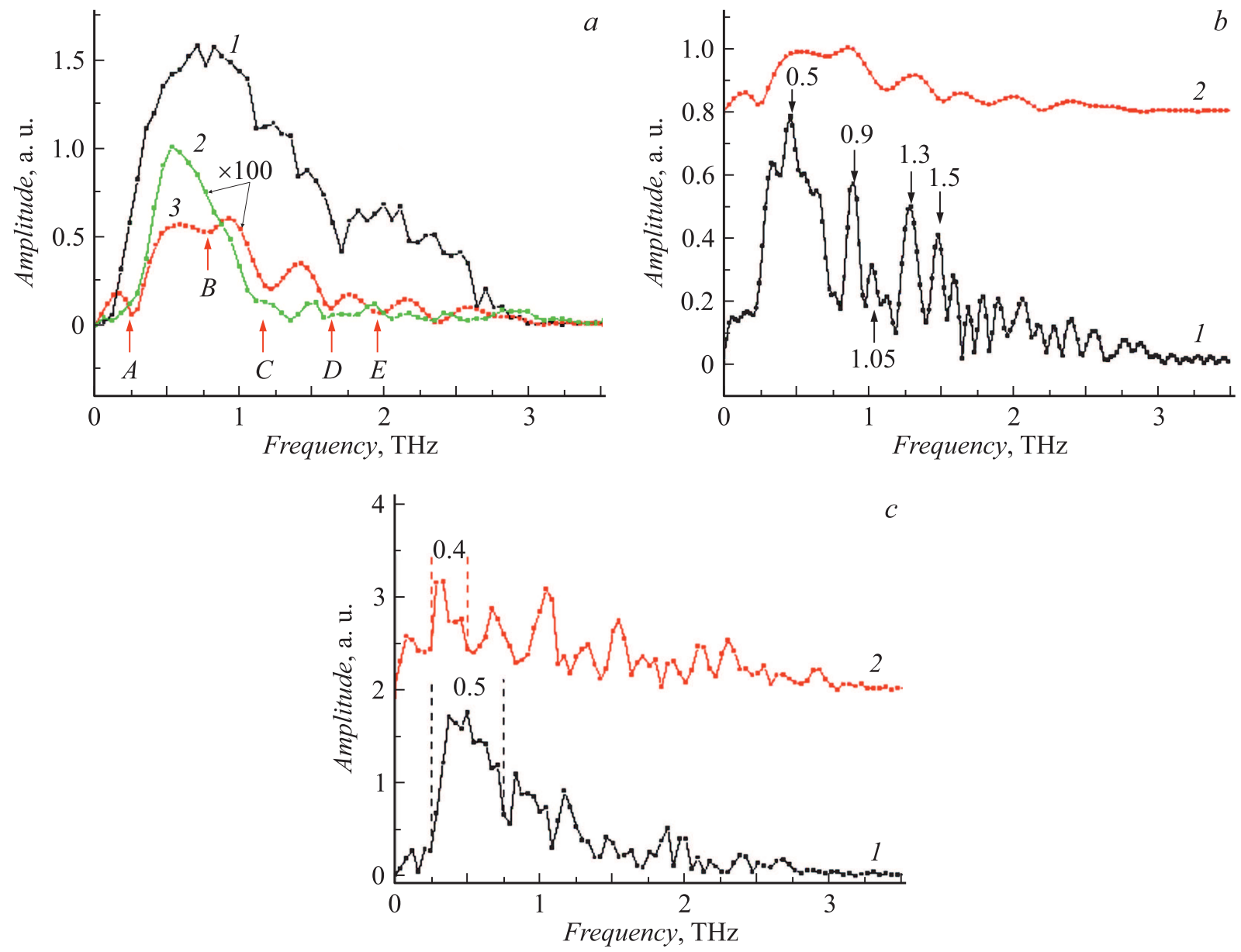

Рис. 2. Терагерцевые спектры: $a-$ исходного THz-излучения, падающего на зонд (кривая 1), дифференциального сигнала, полученного при нахождении зонда над поверхностью золота (кривая 2) и поверхностью неструктурированного графена (кривая 3); $b$ - дифференциального сигнала, полученного при нахождении зонда над поверхностью графеновой ленты шириной $3.6 \mu$ т (кривая 1) и поверхностью неструктурированного графена (кривая 2), верхняя кривая приподнята по оси ординат на 0.8 а.u.; $c-$ дифференциального сигнала, полученного при нахождении зонда над поверхностью графеновой ленты шириной $3.6 \mu \mathrm{m}$ (кривая 1 ) и при смещении на $4 \mu \mathrm{m}$ (лента шириной $6 \mu \mathrm{m}$ ) вниз вдоль оси $y$, см. рис. 1 (кривая 2), верхняя кривая приподнята по оси ординат на 2 a.u.

пропускание THz-излучения в графене, на поверхность которого адсорбировались молекулы различных газов.

Последующие исследования ближнепольного взаимодействия со структурированным графеном (графеновыми лентами) показали, что, во-первых, сила взаимодействия ближнепольной компоненты терагерцевого электромагнитного поля с графеновой лентой имеет по порядку ту же величину, что и в случае взаимодействия с поверхностью металла, а во-вторых, происходит изменение спектра THz-импульса, конвертированного зондом терагерцевого ближнепольного микроскопа. Кроме того, максимальная амплитуда волновой формы ближнепольного THz-сигнала для графеновой ленты была примерно в 3 раза больше, чем соответствующее значение для неструктурированного графена. В ходе эксперимента было обнаружено, что в спектре THz-излучения, рассеянного на системе зонд-объект, существуют особенности, которые отсутствуют в спектре исходного THz-из- лучения (рис. $2, b$ ). В области $0.2-1.6 \mathrm{THz}$ появились резонансные пики $(0.5,0.9,1.05,1.3,1.5 \mathrm{THz})$, которых нет ни в ближнепольном отклике от поверхности металла $(\mathrm{Au})$, ни в отклике от неструктурированного графена. Отметим, что положение этих пиков $\left(\omega_{n}\right)$ хорошо согласуется с зависимостью, описывающей плазмонные моды в графеновой ленте: $\omega_{n} \sim(2 n-1)^{1 / 2} \omega_{1}$, где $n=2,3 \ldots$, а $\omega_{1}$ - частота первой плазмонной моды [15]. Кроме того, было обнаружено, что спектр рассеянного от зонда THz-импульса зависит от ширины ленты $W$ примерно как $\omega_{1} \sim W^{-1 / 2}$ [15], например $\omega_{1}(W(3.6 \mu \mathrm{m})) / \omega_{1}(W(6 \mu \mathrm{m}))=0.5 / 0.4 \sim(6 / 3.6)^{1 / 2}$ (рис. $2, c$ ). Положения пиков 0.5 и $0.4 \mathrm{THz}$ отвечают серединам соответствующих первых полос (края полосы помечены штриховыми линиями) на рис. 2,c. Пики на рис. $2, b$ и $c$ имеют сложную форму. Для характеризации положения пиков целесообразно ввести понятие полосы, середина которой и соответствует положению пика. Края 
полосы определялись как края пика при условии, что интенсивность краев не превышает 50\% от абсолютной интенсивности пика.

Появление новых пиков, возможно, обусловлено возбуждением плазменных колебаний в графене за счет взаимодействия ближнего поля, создаваемого зондом при облучении THz-излучением, с электронной плазмой в графене и проявлением интерференции плазменных волн в резонаторе, которым является сама графеновая лента. Плазменные волны в THz-диапазоне, совпадающем с диапазоном на рис. 2, ранее наблюдались при их генерации на границах раздела графенового слоя [16]. Следует отметить, что кривые 1 на рис. $2, b$ и $c$ получены на одной и той же ленте, но в разные дни и при различном расположении зонда относительно краев ленты. Различия в спектрах, вероятно, связаны с локальными особенностями графена в области измерения спектров (адсорбированные из атмосферы молекулы на поверхности, рельеф $\mathrm{SiC}$-подложки). Расчет точных значений резонансных частот $\left(\omega_{p l}\right)$ для ленты шириной $W$ в нашем случае затруднен вследствие возможного изменения концентрации электронов в ленте после ЛАО, а также отсутствия информации о величине сдвига фазы при отражении волны на границе лента/оксид графена. Данным исследованиям будут посвящены следующие публикации.

Таким образом, в работе сообщается об экспериментальных результатах рассеяния и ближнепольного взаимодействия терагерцевого электромагнитного поля с графеновыми лентами вблизи зонда атомно-силового микроскопа. Было показано, что сила взаимодействия ближнепольной компоненты терагерцевого электромагнитного поля с графеновыми лентами имеет по порядку ту же величину, что и в случае взаимодействия с поверхностью металла, что, по-видимому, обусловлено сильным плазмонным откликом на THz-частотах. Обнаружено возникновение резонансных пиков в области $0.2-1.6 \mathrm{THz}$ в спектрах рассеяния THz-излучения на лентах графена в присутствии зонда.

\section{Финансирование работы}

Работа выполнена при частичной поддержке программы Президиума РАН № 13 „Основы высоких технологий и использование особенностей наноструктур в науках о природе“, а также РФФИ и НЦНИ в рамках нучного проекта № 18-51-16002. П.А.А. и Б.Р.Б. благодарят за поддержку в рамках гранта Президента РФ МK-5852.2018.2.

\section{Конфликт интересов}

Авторы заявляют, что у них нет конфликта интересов.

\section{Список литературы}

[1] Vicarelli L., Vitiello M., Coquillat D., Lombardo A., Ferrari A.C., Knap W., Polini M., Pellegrini V., Tredicucci A. // Nature Mater. 2012. V. 11. P. 865-871.

[2] Cai X., Sushkov A.B., Suess R.J., Jadidi M.M., Jenkins G.S., Nyakiti L.O., Myers-Ward R.L., Li S., Yan J., Gaskill D.K., Murphy T.E., Drew H.D., Fuhrer M.S. // Nature Nanotechnol. 2014. V. 9. P. $814-819$.

[3] Grigorenko A., Polini M., Novoselov K. // Nature Photon. 2012. V. 6. P. $749-758$.

[4] Constant T.J., Hornett S.M., Chang D.E., Hendry E. // Nature Phys. 2016. V. 12. P. 124-127.

[5] Yao B., Liu Y., Huang S.-W., Choi C., Xie Z., Flores J.F., Wu Y., Yu M., Kwong D.-L., Huang Y., Rao Y., Duan X., Wong C.W. // Nature Photon. 2018. V. 12. P. 22-28.

[6] Cai X., Sushkov A.B., Jadidi M.M., Nyakiti L.O., MyersWard R.L., Gaskill D.K., Murphy T.E., Fuhrer M.S., Drew H.D. // Nano Lett. 2015. V. 15. P. 4295-4302.

[7] Otsuji T., Popov V., Ryzhii V. // J. Phys. D: Appl. Phys. 2014. V. 47. P. 094006.

[8] Chen J., Badioli M., Alonso-González P., Thongrattanasiri S., Huth F., Osmond J., Spasenović M., Centeno A., Pesquera A., Godignon P., Elorza A.Z., Camara N., García de Abajo F.J., Hillenbrand R., Koppens F.H.L. // Nature. 2012. V. 487. P. 77-81.

[9] Давыдов В.Ю., Усачёв Д.Ю., Лебедев С.П., Смирнов А.Н., Левичкий В.С., Елисеев И.А., Алексеев П.А., Дунаевский М.С., Вилков О.Ю., Рыбкин А.Г., Лебедев А.А. // ФТП. 2017. T. 51. B. 8. C. $1116-1124$.

[10] Алексеев П.А., Бородин Б.Р., Дунаевский М.С., Смирнов А.Н., Давыдов В.Ю., Лебедев С.П., Лебедев А.А. // Письма в ЖТФ. 2018. Т. 44. В. 9. С. 34-40.

[11] Трухин В.Н., Андрианов А.В., Быков В.А., Голубок А.О., Зиновьев Н.Н., Самойлов Л.Л., Сапожников И.Д., Трухин А.В., Фельштын М.Л. // Письма в ЖЭТФ. 2011. Т. 93. B. 3. C. $134-138$.

[12] Трухин В.Н., Голубок А.О., Лютецкий А.В., Матвеев Б.А., Пихтин Н.А., Самойлов Л.Л., Сапожников И.Д., Тарасов И.С., Фельштын М.Л., Хорьков Д.П. // Изв. вузов. Радиофизика. 2011. Т. 54. № 8-9. С. 640-648.

[13] Yang Y., Shutler A., Grischkowsky D. // Opt. Express. 2011. V. 19. P. $8830-8838$.

[14] Docherty C.J., Lin C.-T., Joyce H.J., Nicholas R.J., Herz L.M., Li L.-J., Johnston M.B. // Nature Commun. 2012. V. 3. P. 1228.

[15] Mikhailov S.A., Savostianova N.A. // Phys. Rev. B. 2005. V. 71. P. 035320.

[16] Mitrofanov O., Yu W., Thompson R.J., Jiang Y., Brener I., Pan W., Berger C., De Heer W.A., Jiang Z. // Appl. Phys. Lett. 2013. V. 103. P. 111105. 